\title{
0 laboratório clínico livre de mercúrio
}

\author{
The clinical laboratory free of mercury
}

Evelyn Rodrigues'; Lia Marques de Oliveira Lavorato²; Roberto Carlos Dionizio Novais ${ }^{3}$; Luciane Zgoda Bussmann ${ }^{4}$; Maria Elizabete Mendes ${ }^{5}$ Nairo Massakazu Sumita ${ }^{6}$

unitermos
Mercúrio
Exposição
Toxicidade
Risco à saúde
Risco ao meio ambiente

\section{resumo}

Introdução: No último século, os níveis de mercúrio no meio ambiente triplicaram, aumentado o risco de contaminação do ser humano. No ambiente, o mercúrio contamina os lençóis freáticos, bem como rios e mares e entra na cadeia alimentar pela ingestão de peixes contaminados. No organismo, afeta o sistema nervoso central (SNC). A exposição aguda, por inalação de vapores de mercúrio, acarreta astenia, fadiga, anorexia, perda de peso e perturbações gastrointestinais. O diagnóstico da contaminação é realizado pela análise em amostras de cabelo/sangue. A substituição dos equipamentos contendo mercúrio utilizados em serviços de saúde é procedimento fundamental para a redução dos riscos ocupacionais e ambientais. Objetivo: Descrever o processo de implantação do programa de "Mercúrio Zero" na Divisão de Laboratório Central do Hospital das Clínicas da Faculdade de Medicina da Universidade de São Paulo (DLC/HC-FMUSP). Métodos: O projeto foi desenvolvido em um período de três anos (2008-2010). Na elaboração do projeto, foram definidos planos de ações, incluindo um programa de treinamento e capacitação de uma equipe de trabalho responsável pela execução do processo de substituição dos equipamentos e reagentes. Resultados: Ao final do projeto de implantação, a DLC/HC-FMUSP foi laureada com uma menção honrosa pelo programa Mercúrio Zero do Ministério do Trabalho e Emprego (MTE) por ter cumprido as exigências. Conclusão: Um ambiente laboratorial livre de mercúrio requer compromisso da alta direção e planejamento com ações consistentes, além de maturidade e conscientização de todos os colaboradores acerca do risco representado pelo mercúrio à saúde e ao meio ambiente.

abstract

Introduction: Over the last century, mercury levels in the environment have tripled, increasing the risk of human contamination. Hence, it pollutes groundwater, rivers and seas, and it enters the food chain through the ingestion of contaminated fish. It affects the central nervous system and the inhalation of mercury vapors cause asthenia, fatigue, anorexia, weight loss and gastrointestinal disturbances. The contamination detection is carried out through hair and blood sample analysis. The replacement of mercury-containing equipment used in health services is crucial in order to reduce environmental and occupational hazards. Objective: To describe the implementation of "Zero Mercury" program at the Central Laboratory Division of University of São Paulo Medical School Hospital - CLD/USP-MSH (Divisão de Laboratório Central do Hospital das Clinicas da Faculdade de Medicina da Universidade de São Paulo [DLC/HC-FMUSP]). Methods: The project was developed within the period of three years (2008-2010). During its elaboration, the action plans were defined, including a training program for the team responsible for the implementation of equipment and reagent replacement. Results: By the end of the project, CLD/USP-MSH received an honorable mention by the Brazilian Ministry of Labor and Employment for the fulfillment of "Mercury Zero" program requirements. Conclusion: A mercury-free laboratory environment requires managerial commitment, a consistent action plan and staff awareness of health and environmental risks. key words Mercury

Exposure

Toxicity

Mercury

Health risk

Environmental risk

1. Bióloga; gestora de Meio Ambiente da Divisão de Laboratório Central do Hospital das Clínicas da Faculdade de Medicina da Universidade de São Paulo (DLC/HC-FMUSP).

2. Técnica de laboratório do Serviço de Bioquímica Clínica da DLC/HC-FMUSP.

3. Técnico de laboratório do Serviço de Bioquímica Clínica da DLC/HC-FMUSP.

4. Bióloga da DLC/HC-FMUSP.

5. Doutora em Medicina (Patologia); médica patologista clínica; chefe da Seção Técnica de Bioquímica de Sangue da DLC/HC-FMUSP (LIM-03 da Patologia Clínica); coordenadora do Núcleo de Qualidade e Sustentabilidade da DLC/HC-FMUSP.

6. Doutor em Medicina; professor da disciplina de Patologia Clínica da FMUSP; médico patologista clínico; diretor do Serviço de Bioquímica Clínica da DLC/HC-FMUSP (LIM-03 da Patologia

Clínica); assessor médico em Bioquímica Clínica do Fleury Medicina e Saúde. 


\section{Introdução}

No último século, os níveis de mercúrio no meio ambiente triplicaram e esse crescimento alarmante aumentou, exponencialmente, o risco de contaminação para o ser humano, bem como para a vida selvagem ${ }^{(21,22)}$. Trata-se de uma ameaça que submete todo o ecossistema a uma exposição perigosa e potencialmente fatal, já que o mercúrio é uma substância cumulativa e facilmente transportada dentro do organismo.

O mercúrio é um elemento metálico sui generis. Apresenta-se na forma líquida à temperatura ambiente, com ponto de fusão a $-38,87^{\circ} \mathrm{C}$ e ponto de ebulição a $356,58^{\circ} \mathrm{C}$. É um metal prateado, denso e possui elevada tensão superficial. Muitas características mineralógicas simplesmente não se aplicam ao mercúrio pelo fato de se apresentar na forma líquida. Não há definição do grau de dureza. O mercúrio não possui estrutura cristalina ou plano de clivagem. Dissolve-se facilmente em ouro, prata, chumbo e metais alcalinos, formando ligas relativamente consistentes, conhecidas como amálgamas ${ }^{(19,20)}$.

Em contato com o ar, recobre-se com uma película acinzentada, transformando-se em óxido de mercúrio, o que o torna volátil. À temperatura de $350^{\circ} \mathrm{C}$, oxida-se rapidamente, produzindo óxido de mercúrio vermelho, mais nocivo do que o óxido de mercúrio, portanto não se recomenda a incineração de produtos que o contenham ${ }^{(3)}$.

A substância simples e os sais de mercúrio são os principais responsáveis pela contaminação ocupacional, enquanto os compostos orgânicos de mercúrio, predominantemente o metilmercúrio, são responsáveis pela contaminação ambiental. Uma característica comum às duas formas de mercúrio é que ambas podem ultrapassar a barreira placentária, afetando seriamente o feto ${ }^{(4,26)}$.

No ambiente, o mercúrio contamina os lençóis freáticos, assim como rios e mares. Dessa forma, entra na cadeia alimentar pela ingestão, por exemplo, de peixes contaminados e afeta, diretamente, o sistema nervoso central (SNC) humano. O diagnóstico da contaminação por esse agente é realizado facilmente pela determinação do mercúrio no cabelo ou no sangue, pela técnica de espectrometria de massas com plasma indutivamente acoplado $(\text { ICP-MS })^{(3,20)}$.

O mercúrio é caracterizado como um agente tóxico celular, capaz de provocar a destruição de tecidos com a formação de proteínas mercuriais solúveis, além da inibiç̧ão de sistemas enzimáticos essenciais para a oxidação celular. Ao nível da via digestiva, exerce ação cáustica, respondendo pelos transtornos digestivos verificados na forma aguda de intoxicação. No organismo, o mercúrio age como composto tóxico protoplasmático, ou seja, age diretamente sobre as células, principalmente, naquelas ricas em protoplasma. Os compostos solúveis de mercúrio são absorvidos pelas mucosas, e os insolúveis, pela pele e glândulas sebáceas. Os vapores são absorvidos por via respiratória ${ }^{(30,31)}$.

Uma vez absorvido, o mercúrio passa para o sangue, é oxidado, ligando-se às proteínas do plasma e aos eritrócitos, distribuindo-se pelos tecidos, concentrando-se em rins, fígado, medula óssea, parte superior do aparelho respiratório, aparelho digestivo, sistema nervoso central e ossos. A exposição aguda, por inalação de vapores de mercúrio pode acarretar astenia, fadiga, anorexia, perda de peso e perturbações gastrointestinais ${ }^{(7,17,24)}$.

A ingestão de compostos mercuriais, em particular cloreto de mercúrio, provoca úlcera gastrointestinal e necrose tubular aguda $(10,15)$.

No sistema nervoso, o produto tem efeitos desastrosos, podendo causar desde lesões ligadas à coordenação motora até encefalopatia mercurial caracterizada por hiperexcitabilidade, cefaleia, vertigens, angústia, tremores dos dedos e delírios ${ }^{(10)}$.

O tratamento da intoxicação aguda compreende lavagem gástrica, uso de laxantes e eméticos. Como antídoto, pode ser usado o dimercaprol ou British anti-Lewisite (BAL). Deve-se, ainda, fazer tratamento sintomático. Para os casos crônicos recomendam-se o afastamento do paciente do local ou fonte de intoxicação, a manutenção da nutrição por via endovenosa ou oral, o tratamento da disfunção renal, além da terapia de sustentação e administração de substâncias quelantes(3).

$\mathrm{Na}$ área da saúde, o mercúrio pode ser encontrado em diversos reagentes, amálgamas utilizados em odontologia, esfigmomanômetros, manômetros, termômetros, além das lâmpadas fluorescentes ${ }^{(4)}$.

O mercúrio é um metal líquido, pesado e extremamente tóxico que vem sendo utilizado como matéria-prima nas restaurações dentárias de amálgama de prata há mais de um século. Em seu estado líquido é extremamente volátil, oferecendo altos riscos de contaminação durante o seu manuseio, uma vez que a via respiratória é o principal acesso de penetração desse metal no organismo. Os profissionais da equipe de saúde bucal estão diariamente expostos ao mercúrio e aos riscos de sua contaminação. Os riscos referem-se à manipulação do amálgama, a gotas do metal derramadas acidentalmente, à remoção do excesso de mercúrio da 
massa de amálgama, a amalgamadores com vazamento, a condensadores ultrassônicos, a falhas do sistema de sucção quando da remoção de restaurações antigas ou, ainda, aos vapores emanados das "sobras" de amálgama armazenadas inadequadamente nos consultórios. $\mathrm{O}$ ambiente contaminado dos consultórios constitui risco não só para os profissionais, mas também para os pacientes, principalmente aqueles submetidos a procedimentos demorados, ou os que necessitam de retornos constantes. Segundo alguns pesquisadores, as restaurações de amálgama dentário também são fontes potenciais de contaminação pelo mercúrio, que pode ocorrer por meio dos vapores do metal liberados por elas, ou mediante a absorção pela mucosa bucal|(11).

Os esfigmomanômetros com coluna de mercúrio utilizados em hospitais, clínicas e laboratórios apresentam risco de derramamento do metal, gerando impactos para o meio ambiente e para a saúde do trabalhador ${ }^{(23,29)}$. Esse tipo de equipamento ainda é o mais difundido entre os métodos indiretos de aferição da pressão arterial, apesar de ter acurácia limitada(31).

Atualmente existem modelos com dispositivos digitais e o mecânico aneroide, os quais não contêm mercúrio em sua constituição. Importante ressaltar que a validade dos monitores digitais necessita ser confirmada antes do uso(2).

As lâmpadas fluorescentes são caracterizadas como resíduos perigosos por conterem, em sua composição, o gás de mercúrio, cuja toxidade é reconhecida pelo ConseIho Nacional de Meio Ambiente (CONAMA), por meio da Resolução $n^{\circ}$ 007, de 4 de maio de 1994, no item referente à classificação dos "resíduos perigosos".

A Organização Mundial da Saúde (OMS) reconhece o mercúrio como um metal de elevada toxicidade e recomenda à área da saúde a substituição dos aparelhos que o contenham ${ }^{(25)}$.

Os serviços de medicina laboratorial empregam produtos e equipamentos que contêm este metal em sua rotina diária e estes deveriam ser substituídos por outros sem mercúrio para prevenir riscos ocupacionais e ambientais.

Em 2005, o European Environmental Bureau and Mercury Policy Project formou um grupo de trabalho denominado Zero Mercury Work Group (ZMWG), o qual consistia em uma coalizão internacional com cerca de 90 organizações não governamentais, de interesse público, das áreas de saúde e meio ambiente presentes em 45 países em todo o mundo, incluindo o Brasil(22).

O programa tinha como objetivo extinguir a oferta, a demanda e as emissões de mercúrio de todas as fontes antropogênicas. A meta era reduzir o mercúrio do meio ambiente global para o mínimo. Tinha como missão defender e apoiar a adoção e a implementação de um instrumento legalmente vinculante, contendo obrigações de eliminação quando viável e, quando não fosse possível eliminar, reduzir a oferta à demanda global de mercúrio, as emissões antropogênicas ao meio ambiente, a exposição humana e da biodiversidade ao mercúrio( ${ }^{(9)}$.

No Brasil, esse grupo é coordenado pelo Ministério do Trabalho e Emprego (MTE). As instituições que implantam o programa se submetem a uma inspeção por especialistas e, quando aprovadas, podem ser certificadas pelo MTE no Programa de Mercúrio Zero.

A Associação Brasileira de Normas Técnicas (ABNT) NBR $10.004^{(33)}$, norma que trata dos resíduos sólidos, ao estabelecer os limites admissíveis de diversos elementos e substâncias químicas dispostos no meio ambiente, também destaca o mercúrio por seu elevado nível de periculosidade.

Na mesma linha, a Norma Regulamentadora (NR) 15, do Ministério do Trabalho(32), que trata das atividades e operações em locais insalubres, lista o mercúrio como um dos principais agentes nocivos que afetam a saúde do trabalhador.

As lâmpadas que contêm mercúrio são as do tipo fluorescentes, fluorescentes compactas, mistas contendo mercúrio, halógenas, de vapor de mercúrio e mercúrio/ sódio. Largamente utilizadas em todo o país, em razão da possibilidade de desprendimento do mercúrio nelas contidas, apresentam elevado impacto ambiental em função da potencial contaminação do ar, da água, do solo e, por consequência, por gerar malefícios à saúde humana( ${ }^{(30,32)}$.

A fabricação, o transporte, o armazenamento, a separação, o acondicionamento, a reciclagem e a reutilização devem ser feitos de forma tecnicamente segura e adequada. A disposição final dos produtos em aterros deve ser evitada até ser totalmente eliminada, com vistas a prevenir os riscos à saúde humana, dos animais e do meio ambiente terrestre, aéreo e aquático.

Existem empresas especializadas no processo de reciclagem dessas lâmpadas, as quais precisam de licenciamento específico e de tecnologia sofisticada. Por se tratar de um material caracterizado como resíduo perigoso, essas empresas devem estar de acordo com o Decreto Federal $\mathrm{n}^{\circ}$ 97.634, de 10 de abril de 1989(13).

A tecnologia utilizada para reciclagem e reutilização das lâmpadas baseia-se na destilação a vácuo, garantindo a total remoção do mercúrio. O vidro, após a sua completa 
descontaminação, pode ser reutilizado na fabricação de novas lâmpadas ou na produção de esmalte para vitrificação de lajotas cerâmicas. O alumínio é refundido como metal secundário. $O$ mercúrio recuperado é reutilizado por fabricantes de lâmpadas e outras indústrias ${ }^{(29)}$.

\section{Objetivo}

O objetivo deste trabalho é discutir a importância de um ambiente livre de mercúrio pela apresentação de um projeto de implantação do Programa Mercúrio Zero promovido na Divisão de Laboratório Central do Hospital das Clínicas da Faculdade de Medicina da Universidade de São Paulo (DLC/HC-FMUSP).

\section{Projeto e desenvolvimento do Programa Mercúrio Zero}

O Programa Mercúrio Zero foi inserido nas diretrizes estratégicas da DLC/HC-FMUSP e desenvolvido no período de junho de 2008 a maio de 2010.

Numa fase preliminar, foi realizado um diagnóstico inicial, identificando os principais pontos a serem otimizados, estabelecendo-se um planejamento para as ações que deveriam ser implantadas na prática operacional.

Iniciou-se o programa mediante a sensibilização e a capacitação da equipe laboratorial acerca do tema. A conscientização se deu por meio de encontros, seminários e produção de material didático e informativo. Os treinamentos foram focados na importância da substituição dos equipamentos e reagentes contendo mercúrio, além do perigo no seu manuseio. Seguiu-se um levantamento dos processos técnicos e equipamentos que utilizavam o mercúrio. A execução do projeto ficou a cargo do Núcleo da Qualidade e Sustentabilidade e respectivas Comissões de Gestão Ambiental, em parceria com o grupo de Gestão de Equipamentos da DLC/HC-FMUSP.

Nas áreas técnicas, foram revistos procedimentos operacionais e a substituição das metodologias por outras que atendessem os requisitos do programa. A documentação necessária foi elaborada para sistematizar a nova situação que entrou em vigência no laboratório.

Foi criado um fluxo específico para a troca e o descarte de lâmpadas fluorescentes. As unidades inutilizadas passaram a ser armazenadas em local seguro até a retirada e o transporte por empresa terceirizada devidamente licenciada. Foi estabelecido um contrato com uma empresa especializada para retirada, transporte, armazenamento, tratamento e reciclagem das lâmpadas, assim como destinação adequada. Atualmente, as lâmpadas substituídas são recolhidas, procedendo-se ao registro e à totalização ao final de cada mês. $O$ acompanhamento é realizado pela equipe de manutenção predial, sob o gerenciamento do Núcleo da Qualidade e Sustentabilidade da DLC/HC-FMUSP.

Finalmente, houve alterações no processo de aquisições de insumos e equipamentos para o laboratório, tornando-o aderente a esta nova especificação. Os equipamentos e reagentes que utilizavam o mercúrio foram substituídos gradualmente com o respectivo monitoramento de todo o processo de substituição.

Considerando-se a possibilidade de os reagentes conterem mercúrio em sua composição, anualmente realiza-se uma análise físico-química dos efluentes descartados pelos equipamentos automatizados, os quais são encaminhados para incineração. Os critérios utilizados para a interpretação destas análises seguem a legislação CONAMA $357^{(12)}$, art. 34, Valor Máximo Permitido (VMP), e o Decreto Estadual $n^{\circ} 8.468 / 76$, art. 19(14).

As auditorias internas do sistema integrado de gestão passaram a inspecionar as etapas de implantação do Programa Mercúrio Zero, além das vistorias periódicas realizadas pela equipe gestora do programa no laboratório.

Após consolidação do programa, efetivou-se o cadastramento da instituição no MTE, solicitando a auditoria externa por profissional especialista. A auditoria seguiu uma lista de verificação específica e foi realizada em todas as áreas do laboratório, resultando em um relatório denominado "Il inquérito sobre uso de aparelho com mercúrio". Após anuência e assinatura dos documentos, o relatório foi encaminhado para o Programa Nacional de Mercúrio na Delegacia Regional do Trabalho no Estado de São Paulo. O processo de certificação foi finalizado após três meses com a emissão de um Certificado de Menção Honrosa pelo MTE.

\section{Estratégias e planos de ação}

- Programa de treinamento: o sucesso do programa deveu-se ao treinamento intensivo e à conscientização acerca do perigo no manuseio de reagentes e equipamentos contendo mercúrio. $\mathrm{O}$ treinamento gerou uma carga horária de 20 horas por funcionário por ano, envolvendo todos os 480 colaboradores, totalizando 9.600 horas de treinamento. Os temas abordados focaram os seguintes tópicos, entre outros: características físico-químicas do 
mercúrio, impactos ambientais, reflexos à saúde e à segurança ocupacional, intoxicações mercuriais, usos do mercúrio em serviços de saúde e no laboratório clínico.

- Equipamentos substituídos: no primeiro ano foram substituídos 140 termômetros, finalizando-se a troca de mais 60 unidades no segundo ano por mais 200 termômetros digitais, os quais foram instalados em freezers, geladeiras, banhos-maria, banhos secos, estufas e para aferir a temperatura ambiente. Foram adquiridos seis esfigmomanômetros digitais. Em relação às vantagens da substituição dos esfigmomanômetros com coluna de mercúrio por modelos digitais podemos enumerar as seguintes: os dispositivos são validados para o uso na prática de saúde, são automáticos, não invasivos, precisos, rápidos, de fácil manuseio e de custo relativamente baixo ${ }^{(14)}$. O custo do projeto referente às substituições e calibrações totalizou um montante de, aproximadamente, US\$10 mil.

- Destinação dos resíduos: ao analisar o impacto ambiental dos efluentes gerados pelos equipamentos à luz das legislações aplicáveis ao descarte de resíduos químicos, optou-se por enviar os resíduos para incineração, pois a presença de mercúrio nas águas, mesmo que em pequenas quantidades, representa um grande problema ecológico devido à sua bioconcentração. Assim, os organismos situados no final da cadeia alimentar apresentam uma concentração mais elevada e, por vezes, perigosa para o próprio animal ou para os que dele se alimentam, originando sérios problemas de saúde pública, podendo intoxicar comunidades inteiras, além dos prejuízos econômicos que daí possam advir(8). Para que esses resíduos fossem encaminhados para incineração, fazia-se necessária uma análise físico-química dos efluentes dos equipamentos. Foi observado que o nível de mercúrio encontrado (VPM) estava abaixo do que é estipulado pelas legislações aplicáveis. No entanto, seguindo a norma da nossa instituição, optamos por encaminhar todo o efluente para incineração, sendo que o monitoramento é realizado pelo certificado de destruição emitido pela empresa prestadora do serviço.

- Documentos e registros da qualidade: dois novos documentos foram inseridos no Programa de Gerenciamento de Documentos da DLC/HC-FMUSP dentro do Manual de Segurança. O primeiro documento foi intitulado "Descarte de lâmpadas fluorescentes", que descreve todo o processo de descarte e reciclagem das lâmpadas retiradas do laboratório e os respectivos registros pertinentes. O segundo documento intitulou-se "Programa Mercúrio Zero", no qual se ressalta a importância da exclusão do mercúrio no laboratório clínico e na vida diária. Diversos colaboradores, uma vez conscientizados dos riscos, passaram a substituir termômetros de mercúrio por outros digitais, reduzindo o risco de contaminação de seus familiares.

\section{Conclusão}

Um ambiente laboratorial livre de mercúrio requer um compromisso da alta direção e um planejamento com planos de ações consistentes. A implantação de um projeto necessita da conscientização de todos os colaboradores para o risco potencial do mercúrio à saúde humana e, principalmente, para o meio ambiente.

\section{Referências}

1. ASSOCIAÇÃO BRASILEIRA DE NORMAS TÉCNICAS. NBR 10004: Classificação de Resíduos. Rio de Janeiro: 2004a. p. 71.

2. ASSOCIAÇÃO DE COMBATE AOS POLUENTES. Disponível em: <http://www.acpo.org.br/site_mercurio>. Acesso em: 18 dez. 2010.

3. AZEVEDO, A. F. Toxicologia do mercúrio. São Carlos: Rima, 2004.

4. BARBOSA, A.C.; GARCIA, A. M. E.; SOUZA, J. R. Mercury contamination in hair of riverine populations of Apiacás Reserve in the Brazilian Amazon. Water, Air and Soil Pollution, v. 97, n. 1-2, p. 1-8, 1997.
5. BRASIL. Norma Regulamentadora 15. Limites de tolerância para ruído contínuo ou intermitente. Portaria n 3.214 , de 8 de junho de 1978. Segurança e Medicina do Trabalho, v. 16, p. 123-34, 1998.

6. BUSCHINELLI, J. T. P. Intoxicação por mercúrio metálico. FUNDACENTRO. Divisão de Medicina do Trabalho. Setor de Doenças Ocupacionais, 1991. 20p.

7. CÂMARA, V. M.; COREY, G. Epidemiologia e meio ambiente: o caso dos garimpos de ouro no Brasil. México: Centro Pan-Americano de Ecologia Humana e Saúde, 1992.

8. CANZANELLO V. J.; JENSEN, P. L.; SCHWARTZ, G. L. Are aneroid sphygmomanometers accurate in hospital and 
clinic settings? Arch Intern Med, v. 161, p. 729-31, 2001.

9. CARNEIRO, M. T. W. D. et al. Intervalos de referência para elementos menores e traço em cabelo humano para a população da cidade do Rio de Janeiro - Brasil. Química Nova, v. 25, n. 1, p. 37-45, 2002.

10. CHANG, L. W. The concept of direct and indirect neurotoxicity and the concept of toxic metal essencial element: interactions as a common biomechanism underlying metal toxicity. In: The vulnerable brain and environmental risks. New York: Plenum, 1992.

11. CLARO, F.A. et al. Mercúrio no amálgama odontológico: riscos da exposição, toxicidade e métodos de controle. Revisão da literatura. Rev. Biociência, v. 9, n. 1, p. 47-54, 2003.

12. CONSELHO NACIONAL DE MEIO AMBIENTE [CONAMA]. Resolução $n^{\circ}$ 357, de 17 de março de 2005: dispõe sobre a classificação dos corpos de água e diretrizes ambientais para o seu enquadramento, bem como estabelece as condições e padrões de lançamento de efluentes, e dá outras providências. Brasília (DF); Diário Oficial da União.

13. Decreto Federal $n^{\circ} 97.634$, de 10 de abril de 1989. Dispõe sobre o controle da produção e da comercialização de substância que comporta risco para a vida, a qualidade de vida e o meio ambiente, e dá outras providências.

14. ESTADO DE SÃO PAULO. Decreto Estadual $n^{\circ} 8.468$, de 8 de setembro de 1976: aprova o regulamento da Lei $n^{\circ}$ 997, de 31 de maio de 1976, que dispõe sobre a prevenção e controle da poluição do meio ambiente. São Paulo (SP): Diário Oficial do Estado de São Paulo.

15. FERRARI, I. et al. Investigação de genotoxicidade em pessoas profissionalmente expostas ao mercúrio em garimpos da Amazônia. Rev. Panam Salud Pública [online], v. 16, n. 6, p. 415-9, 2004.

16. FREITAS, N. N. B. et al.Vigilância epidemiológica e sanitária da intoxicação por mercúrio (hidrargirismo). São Paulo: Secretaria de Estado dos Negócios da Saúde, 1992.

17. GRILLO, S. et al. Exposição profissional ao mercúrio em ambiente hospitalar. II Congresso Brasileiro Saúde Coletiva: 76. Porto Alegre, RS. 1992.

18. HACON, S. et al. Riscos e conseqüências do uso do mercúrio. Rio de Janeiro: FINEP, 1990. 314 p.

19. IDE, C. W. Mercury hazards arising from the repair of sphygmomanometers. Br Med J (Clin Res Ed), v. 293, p. 1409-10, 1986.
20. International Persistent Organic Pollutants Elimination Network. Disponível em: <http://www.ipen.org/ ipenweb>. Acesso em: 10 dez. 2010.

21. LANGWORTH, S. et al. Biological monitoring of environmental and occupational exposure to mercury. Archives Occupational Environmental Health, v. 63, p. 161-7, 1991.

22. LEGAL, I. Resultados clínicos e dosimétricos. Rev Bras Saúde Ocup, v. 75, n. 20, p. 54-60, 1992.

23. MALM, O. Gold mining as a source of mercury exposure in the Brazilian Amazon. Environmental Research, v. 77, p. 73-78, 1998.

24. MENEZES, A. M. B. et al.Validade de um monitor digital de pulso para mensuração de pressão arterial em comparação com um esfigmomanômetro de mercúrio. Arq Bras Cardiol, v. 94, n. 3, 2010.

25. OMS. Environmental Health Criteria 101: Methyl mercury. Geneva: Organização Mundial da Saúde; 1990.

26. QUELHAS, M. C. F. Os riscos do uso do mercúrio metálico para medir a pressão arterial média (PAM). Rev Paul Enferm, v. 70-4, 1991.

27. REDE BRASILEIRA DE JUSTIÇA AMBIENTAL. Disponível em: <http://www.justicaambiental.org. br/_justicaambiental>. Acesso em: 10 jan. 2011.

28. REIS, R. S; LAMAS, J. L. T. Uso de dispositivo automático de medida de pressão arterial em crianças entre 4 e 13 anos. Rev. Eletr. Enf [Internet], v. 11, n. 4, p. 794-800, 2009.

29. XELEGATI, R; ROBAZZI, M. L. C. C. Riscos químicos a que estão submetidos os trabalhadores de enfermagem: uma revisão de literatura. Rev Latino-Am Enfermagem, v. 11, n. 3, p. 350-6, 2003.

30. ZAVARIZ, C. Avaliação da utilização industrial de mercúrio metálico no estado de São Paulo e aplicação de metodologia de intervenção nas condições de trabalho. São Paulo, 1994. 200 p.

31. ZAVARIZ, C.; GLINA, D. M. R. Avaliação clínica-psicológica de trabalhadores expostos a mercúrio metálico em indústria de lâmpadas elétricas. Revista Saúde Pública, v. 26, n. 5, p. 356-65, 1992.

32. ZAVARIZ, C.; GLINA, D. M. R. Effects of occupational exposure to mercury in workers at a light bulb factory in Santo Amaro, São Paulo, Brazil. Cad Saúde Públ, Rio de Janeiro, v. 9, n. 2, p. 117-29, 1993.

33. ZERO MERCURY GLOBAL CAMPAIGN. Disponível em: <http://www.zeromercury.org>. Acesso em: 15 jan. 2011. 